\title{
DISPOSITIVO-BULLYING E GOVERNAMENTALIDADE SECURITÁRIA: DIÁLOGOS COM O PENSAMENTO DE MICHEL FOUCAULT.
}

\author{
João Paulo Pereira Barros ${ }^{1}$
}

\begin{abstract}
RESUMO:
De meados do século XX e ao longo da primeira década do século XXI, a temática do bullying vem ganhando destaque crescente nos meios de comunicação de massa, entre familiares e entre os profissionais da saúde, da educação e da justiça que trabalham com segmentos infanto-juvenis e que são convocados a atuar em contextos educacionais e escolares. Tendo em vista a necessidade de um debate crítico a respeito desse efervescente tema, este artigo tem o intuito de apresentar conexões entre modos de operação do dispositivo-bullying e as estratégias de governamentalidade neoliberal articuladas a mecanismos de segurança na contemporaneidade. Para tanto, serão traçados diálogos com o pensamento arquegenealógico de Michel Foucault e suas ressonâncias em campos como a Psicologia e a Educação. Sob a referência foucaultiana, o reposicionamento do bullying como dado auto evidente para a condição de "dispositivo" implica pensá-lo como uma rede tecida entre elementos heterogêneos - discursos, instituições, regulamentações, leis e decisões administrativas, assim como enunciados científicos e proposições de ordem moral sobre a violência entre pares no contexto escolar/educacional. Para o alcance do objetivo proposto, o texto, em um primeiro momento, porá em análise a relação entre a consolidação da categoria bullying para dar conta de determinadas modulações de violência entre pares em contextos escolares/educacionais e a emergência das tecnologias biopolíticas de poder características dos dispositivos de segurança. Em um segundo momento, discutirá como certos modos de operação do dispositivo bullying tem oportunizado a intensificação de processos de judicialização da vida, caracterizados pelo enquadramento jurídico-legal cada vez mais minucioso e insidioso das relações sociais no cotidiano.
\end{abstract}

Palavras-chave: bullying; escola; Foucault; segurança; judicialização.

\section{BULLYING DEVICE AND SAFE GOVERNAMENTALITY: DIALOGUES OF MICHEL FOUCAULT'S THINKING}

\begin{abstract}
:
From the mid-twentieth century and throughout the first decade of the twenty-first century, the issue of bullying has been gaining increasing prominence in the mass media, among family members and among health, education and justice professionals working with children and youth segments. who are called to work in educational and school contexts. Given the need for a critical debate on this effervescent theme, this article aims to present connections between modes of operation of the bullying device and strategies of neoliberal governmentality linked to security mechanisms in contemporary times. For this, dialogues will be drawn with Michel Foucault's archegenealogical thinking and its resonances in fields such as Psychology and Education. Under the Foucaultian reference, the repositioning of bullying as self-evident data for the condition of "device" implies thinking it as a network woven between heterogeneous elements - discourses, institutions, regulations, laws and administrative decisions, as well as scientific statements and propositions on peer violence in the school / educational context. To reach the proposed goal, the text will initially analyze the relationship between the consolidation of the bullying category to account for certain modulations of violence between peers in school / educational contexts and the emergence of characteristic biopolitical technologies of power safety devices. In a second moment, it will discuss how certain modes of operation of the bullying device have facilitated the intensification of processes of judicialization of life, characterized by the ever more detailed and insidious juridical

\footnotetext{
${ }^{1}$ Professor Adjunto do Departamento de Psicologia e vice coordenador do Programa de Pós-Graduação em Psicologia da Universidade Federal do Ceará (UFC). Membro do Colegiado da Coordenação do Curso de Psicologia da UFC, coordenando a unidade curricular; Processos Psicossociais; Doutor em Educação, mestre e graduado em Psicologia pela Universidade Federal do Ceará (UFC). Especialista em Saúde Mental pela Universidade Estadual do Ceará (UECE). Email: jppbarros@yahoo.com.br.
} 
framework

of

social

relations

in

daily

life.

Keywords: bullying; school; Foucault; safety; judicialization.

\section{Introdução}

No final do século XX e ao longo da primeira década do século XXI, a temática do bullying vem ganhando destaque crescente nos meios de comunicação de massa, entre familiares e entre os profissionais da saúde, da educação e da justiça que trabalham com segmentos infanto-juvenis e que são convocados a atuar em contextos educacionais e escolares. Diversos episódios violentos de comoção internacional e nacional têm contribuído para que o aquecimento de debates sobre esse assunto.

Um dos episódios de maior destaque ficou conhecido como "Caso Columbine": em 1999, dois estudantes mataram a tiros 13 pessoas em uma escola nos Estados Unidos e depois se suicidaram. A mídia e os "especialistas" convocados por ela ocuparam-se em disseminar a inteligibilidade segundo a qual o massacre teria sido o resultado de um plano de vingança elaborado por aqueles dois jovens em resposta às humilhações que sofriam de seus pares. Assim, em que pesem alguns posicionamentos dissonantes, como o exibido no documentário "Tiros em Columbine", de 2002, causou-nos espécie a hipervisibilidade ao famigerado bullying que se atrelou ao caso, contrastando com uma exígua problematização do jogo comercial que incitava o medo e a insegurança como pretextos para o indiscriminado consumo de armas nos EUA (MARAFON, 2013a; BARROS, 2014).

No Brasil, um dos episódios mais comentados nesse sentido, ocorrido em abril de 2011, também chamou atenção mundial: em Realengo, bairro da cidade do Rio de Janeiro, um ex-aluno invadiu sua antiga escola e desferiu vários disparos contra os presentes, matando 12 adolescentes. Em vídeos gravados nas vésperas do ataque, o autor dos disparos afirmou que sofria humilhações sistemáticas quando estudante daquele estabelecimento escolar, o que fez com que também ganhasse força a intepretação linear de que o bullying teria causado o massacre naquela escola (BARROS, 2014).

Mais recentemente, em outubro de 2017, outro episódio ocorrido no Brasil obteve ampla repercussão midiática: na cidade de Goiânia, um adolescente de 14 anos, filho de policiais, lançou mão de uma arma que trouxe de sua casa para atirar em dois

\begin{tabular}{|l|l|l|l|l|}
\hline Q Rovista 2 ialectus & Ano 4 & n. 11 & Agosto - Dezembro 2017 & p. 50-68 \\
\hline
\end{tabular}


colegas em uma escola particular e deixou outros quatro alunos em estado grave. Não demorou para que diversos portais de notícias e jornais de amplo alcance apontassem que o episódio teria sido "motivado por bullying" e ratificassem que "precisamos falar sobre bullying", em um contexto no qual cada vez mais a escola figura associada à "insegurança".

Tendo em vista a necessidade de um debate crítico a respeito desse efervescente tema, este artigo tem o intuito de apresentar conexões entre modos de operação do dispositivo-bullying e as estratégias de governamentalidade neoliberal articuladas a mecanismos de segurança na contemporaneidade. Trata-se de um desdobramento da tese de doutorado realizada por Barros (2014) e articula produções subsequentes (BARROS, 2016; BARROS, 2017) sobre a relação entre bullying como categoriadobradiça de processos de medicalização e judicialização da vida, no contexto de uma governamentalidade securitária.

Para tanto, serão traçados diálogos com o pensamento de Michel Foucault e suas ressonâncias em campos como a Psicologia e a Educação. Assim, além de enfocarmos reflexões arquegenealógicas daquele pensador francês, serão trazidas à baila produções que se dedicam a investigar os modos de subjetivação infanto-juvenis e o território escolar a partir dos estudos foucaultianos.

Ao esclarecer sobre os direcionamentos de seus estudos, Foucault (1995, p. 288289) serve de inspiração para o delineamento da proposta deste artigo:

\footnotetext{
Um dos meus objetivos é mostrar às pessoas que um bom número de coisas que fazem parte de sua paisagem familiar - que elas consideram universais são o produto de certas transformações históricas bem precisas. Todas as minhas análises se contrapõem à ideia de necessidades universais na existência humana. Elas acentuam o caráter arbitrário das instituições e nos mostram de que espaço de liberdade ainda dispomos, quais são as mudanças que podem ainda se efetuar.
}

Em um dos pontos de sua tese, Barros (2014) realiza uma análise arquegenealógica das condições de emergência da noção de bullying com subcategoria de violência, apontando jogos de saber-poder-subjetivação implicados no tratamento de certos fenômenos entre segmentos infanto-juvenis na escola sob esse enquadre.

Constituída no âmbito dos estudos foucaultianos, a arquegenalogia pode ser entendida em termos de um exercício analítico das relações de saber-poder em seu caráter produtivo. Nesse sentido, Foucault (2000, p. 28) assevera que:

\begin{tabular}{|l|l|l|l|l|}
\hline Govista 2 Dialectus & Ano 4 & n. 11 & Agosto - Dezembro 2017 & p. 50-68 \\
\hline
\end{tabular}


As forças que se encontram em jogo na história não obedecem nem a uma destinação, nem a uma mecânica, mas ao acaso das lutas. Elas se manifestam como formas sucessivas de uma intenção primordial; como também não têm o aspecto de um resultado. Elas aparecem sempre na álea singular do acontecimento.

Abrir-se a um exercício arquenegealógico para tentar fazer continuidades e descontinuidades acerca da violência escolar implicou não tratar o bullying como um objeto que sempre existiu e que se relativiza com o passar do tempo, mas sim pensar que sua invenção como subcategoria de violência está relacionada a novas instituições, práticas e exigências singulares, bem como enunciados e rituais não necessariamente sempre existentes.

Para Foucault (2000, p. 23), “a emergência é, portanto, a entrada em cena das forças; é sua interrupção, o salto pelo qual elas passam dos bastidores para o teatro, cada uma com seu vigor e sua própria juventude". Fazer uso de tal ferramenta implica, como aponta Lobo (2008), recusarmos dados auto evidentes acerca da violência escolar e investirmos numa abordagem não-linear que trate dos movimentos, das regularidades e das rupturas concernentes à elaboração, composição e recomposição dos regimes de verdade em torno da proveniência ou da emergência do bullying, e não de sua origem, exercitando assim uma "ontologia do presente" (FOUCAULT, 2010).

Assim, para a arquegenealogia ensaiada por Barros (2014), foram importantes para a emergência da categoria bullying a recomposição do território escolar no contemporâneo, na transição de uma sociedade disciplinar para uma sociedade de controle, e a consolidação de uma governamentalidade neoliberal, intimamente conectada a mecanismos de segurança na contemporaneidade. Em seu trabalho, a arquegenealogia cumpriu um papel importante para deslocar o bullying da condição de dado auto evidente, como também fizerem Antunes (2010) e Marafon (2013), reposicionando-o como um dispositivo.

Sob a referência de Foucault (2000), o reposicionamento do bullying para a condição de "dispositivo" implica pensá-lo como uma rede tecida entre elementos heterogêneos - discursos, instituições, regulamentações, leis e decisões administrativas, assim como enunciados científicos e proposições de ordem moral sobre a violência entre pares no contexto escolar/educacional. Entendendo o dispositivo como conceito operatório composto por linhas de visibilidade, de enunciação, de força, de subjetivação

\begin{tabular}{|l|l|l|l|l|}
\hline Qevista Dialectus & Ano 4 & n. 11 & Agosto - Dezembro 2017 & p. 50-68 \\
\hline
\end{tabular}


e de ruptura, a partir do diálogo de Deleuze (1998) com Foucault, podemos considerar o bullying como um emaranhado de práticas de saber-poder e de subjetivação. Portanto, tomar o bullying como um dispositivo possibilita problematizar suas maquinarias e seus efeitos na complexificação de processos de normalização de segmentos infanto-juvenis em territórios educacionais.

Com vistas ao alcance do objetivo proposto, este artigo percorrerá o seguinte caminho. Em um primeiro momento, porá em análise a relação entre a consolidação da categoria bullying para dar conta de determinadas modulações de violência entre pares em contextos escolares/educacionais e a emergência das tecnologias biopolíticas de poder características do que Foucault (2008) cunhou de dispositivos de segurança, a partir de elementos sistematizados por Barros (2017). Em um segundo momento, discutirá como a intensificação de processos de judicialização da vida tem sido oportunizada por certos modos de operação do dispositivo bullying, lançando mão de diálogos com Lobo (2012), Marafon (2013, 2014) e Barros (2016), que também se valem de operadores conceituais do pensamento foucaultiano.

\section{Discussão: relações entre bullying e os dispositivos de segurança}

Quais as relações entre a consolidação da categoria bullying para tratar de determinadas modulações de violência entre pares em contextos escolares/educacionais e a emergência das tecnologias biopolíticas de poder características do que Foucault (2008) cunhou de dispositivos de segurança?

Segundo Foucault (2008), os dispositivos de segurança, cada vez mais em vigor atualmente, caracterizam-se por mecanismos de poder diferentes do código legal, que configura o funcionamento penal arcaico, e dos mecanismos disciplinares, próprios da Modernidade. No entanto, o próprio texto foucaultiano cuida de advertir que a emergência dos dispositivos de segurança não anula as estruturas jurídico-legais ou os dispositivos disciplinares. Até porque, no interior das tecnologias de segurança, há uma inflação dos códigos jurídico-legais para que esse sistema de segurança funcione.

Para exemplificar a inflação jurídico-legal, intimamente relacionada ao recrudescimento de processos de judicialização da vida no contexto das governamentalidades neoliberais, a fabricação da categoria bullying no âmbito do discurso científico e midiático, assim como sua grande repercussão entre familiares e

\begin{tabular}{|l|l|l|l|l|}
\hline Gevista 2 ialectus & Ano 4 & n. 11 & Agosto - Dezembro 2017 & p. 50-68 \\
\hline
\end{tabular}


profissionais da educação e da saúde, fez surgir a lei 13.185/2015, que institui em todo o Brasil o "Programa de Combate à Intimidação Sistemática (Bullying)". A lei se fundamenta justamente na reificação da definição, tipologia e caracterização convencionais de bullying, difundidas como evidência pelas produções majoritárias sobre essa categoria. Nessa lei, "intimidação sistemática" aparece como sinônimo de bullying, na condição de fenômeno que requer medidas de "prevenção" e "combate", mediante "campanhas de educação, conscientização e informação", "nos marcos de uma cultura de paz e tolerância mútua". O programa se propõe, ainda, a "instituir práticas de conduta e orientação de pais, familiares e responsáveis diante da identificação de vítimas e agressores", bem como "dar assistência psicológica, social e jurídica às vítimas e aos agressores", naturalizando e formalizando os enquadres binários, moralizantes, individualizantes e patologizantes encontrados, à exaustão, nos best-seller sobre bullying. A lei não faz menção à violência em sua dimensão pública, tampouco problematiza os territórios em que se produzem tais práticas, resumindo-se a estabelecer que "é dever do estabelecimento de ensino, dos clubes e das agremiações recreativas assegurar medidas de conscientização, prevenção, diagnose e combate à violência e à intimidação sistemática".

Esse quadro ilustra bem o que Lemos et. al (2015, p. 335) consideram como uma das expressões da produção do dispositivo de segurança hoje. Isso porque, "quanto mais lei, maior o raio de punição e de penas a administrar por uma regulamentação das relações cada vez maior. As tensões, disputas e os pequenos desvios rapidamente podem ser capturados em uma rede judiciária e judicializante intensificada".

Paralelamente ao gigantismo dos códigos jurídico-legais, o estabelecimento dos dispositivos de segurança como instrumentos técnicos para o governo das condutas em tempos neoliberais também precisa ativar e refinar mecanismos disciplinares.

Afinal de contas, para de fato garantir essa segurança é preciso apelar, por exemplo, e é apenas um exemplo, para toda uma série de técnicas de vigilância, de vigilância dos indivíduos, de diagnóstico do que eles são, de classificação de sua estrutura mental, de sua patologia própria, etc... Todo um conjunto disciplinar que viceja sob os mecanismos de segurança para fazê-los funcionar (FOUCAULT, 2008, p. 11).

Logo, ao invés de substituição de uma tecnologia de poder por outra, temos, segundo a analítica foucaultiana, técnicas de exercício de poder que vão se correlacionando de modo específico e, assim, aperfeiçoando-se, no bojo das táticas

\begin{tabular}{|l|l|l|l|l|}
\hline Gevista 2 ialectus & Ano 4 & n. 11 & Agosto - Dezembro 2017 & p. 50-68 \\
\hline
\end{tabular}


próprias dos dispositivos de segurança. Por meio desses dispositivos, insere-se, em primeiro lugar, o ilegal numa série de acontecimentos prováveis. Além do mais, as relações de poder frente a isso se inscrevem no que Foucault chama de cálculo de custo, sendo que, "ao invés de instaurar uma divisão binária entre o permitido e o proibido, vai-se fixar de um lado uma média considerada ótima e, depois, estabelecer os limites do aceitável, além dos quais a coisa não deve ir" (FOUCAULT, 2008, p. 9).

Esse raciocínio nos parece muito caro para entender a emergência da categoria bullying e os dispositivos pelos quais os atores escolares tentam geri-lo, como uma espécie de "categoria-dobradiça" entre processos de judicialização e medicalização da vida, segundo destacam Marafon (2013) e Barros (2014). Entendemos que o acontecimento-bullying, mais precisamente os discursos e as práticas institucionais que funcionam mormente no território escolar acionados por essa categoria, é uma potente pista de como os dispositivos de segurança operam por meio do governo de condutas, no âmbito de governamentalidades neoliberais (LEMOS et. al., 2015).

Mas como funcionam as tecnologias de segurança, sob essa ótica? Foucault (2008) ressalta que algumas características diferenciais desses dispositivos podem ser encontradas quanto ao tratamento do espaço e do aleatório, quanto às suas formas de normalização e quanto à correlação entre segurança e população.

Comecemos explicitando, então, que tratamento diferente em relação ao espaço e ao aleatório é dado pelos dispositivos de segurança. Na aula do dia 11 de Janeiro de 1978, Foucault (2008) nos fala que a disciplina implica uma determinada maneira de administrar, organizar e individualizar a multiplicidade, estabelecendo seus pontos de implantação e suas coordenações. Disciplina e Segurança lançariam mão de uma repartição espacial, mas com modos distintos:

[...] enquanto a disciplina arquiteta um espaço e coloca como problema essencial uma distribuição hierárquica e funcional dos elementos, a segurança vai procurar criar um ambiente em função de acontecimentos ou série de acontecimentos ou de elementos possíveis, series que vai ser preciso regularizar num contexto multivalente e transformável. O espaço próprio da segurança remete portanto ao temporal e ao aleatório, um temporal e um aleatório que vai ser necessário inscrever num espaço dado (FOUCAULT, 2008, p. 27).

Foucault usa o exemplo da escassez alimentar para nos mostrar que, nos dispositivos de segurança, as tecnologias e sistemas de governo centram-se cada vez mais num acontecimento eventual, "um acontecimento que poderia se produzir e que se

\begin{tabular}{|l|l|l|l|l|}
\hline Gevista 2 ialectus & Ano 4 & n. 11 & Agosto - Dezembro 2017 & p. 50-68 \\
\hline
\end{tabular}


procura impedir que se produza antes que ele se inscreva na realidade" (FOUCAULT, 2008, p. 44). É algo semelhante a isso a que assistiríamos no caso do bullying e de outras modulações da violência escolar hoje. Para por em funcionamento as tecnologias de segurança frente a uma suposta "epidemia" de bullying escolar, não basta impor uma disciplina, embora esta seja requerida. A segurança buscará acrescentar outros elementos a essas estruturas. Podemos depreender daí que o problema que o fenômenobullying parece encerrar não é mais somente o de excluir ou isolar as crianças ou adolescentes violentos, como outrora se fez com os casos endêmicos e epidêmicos de lepra e peste. Torna-se mister, além disso, saber e mapear quem e quantas pessoas apresentam determinada "patologia" ou comportamento dessa natureza, com que idade, com quais efeitos, a que riscos estão sujeitas, qual a probabilidade de emergir comportamentos violentos na população infanto-juvenil em geral. Toda a mobilização de familiares, profissionais da educação, representantes da justiça e do campo médicopsi em estabelecer os perfis da 'vítima' e do "agressor", de estabelecer formas de punir os responsáveis pelo bullying, mas também de preveni-lo, em defesa da sociedade, mostra bem como os dispositivos de segurança arregimentam técnicas de diversas ordens, psicológicas, médicas e policiais, por exemplo, para diagnosticar, vigiar e transformar indivíduos e grupos (LEMOS et. al., 2015).

Outro elemento característico dos dispositivos de segurança trata-se da correlação entre técnica de segurança e população. Na aula do dia 18 de janeiro de 1978, Foucault (2008), além de seguir elucidando algumas diferenças entre disciplina e segurança, fala-nos dessa relação.

Nas sociedades da segurança, frisa Foucault (2008, p. 56), a população passa a ser o objetivo final. Já a multiplicidade dos indivíduos torna-se pertinente simplesmente “como instrumento, intermédio ou condição para obter algo no nível da população". O pensador francês realça três distinções entre disciplina e segurança. A primeira diferença entre ambas é que a disciplina é centrípeta, porque concentra, isola um espaço e determina seus segmentos, ao passo que a segurança é centrífuga, já que organiza circuitos mais amplos a serem desenvolvidos. A segunda distinção é quanto ao tratamento do detalhe: enquanto nada deve escapar da disciplina, pois esta visa a regulamentar e impedir tudo, inclusive o detalhe, os dispositivos de segurança "deixam fazer", apoiam-se nos detalhes, sem valorizá-los como bons ou ruins em si mesmos, como sublinha Foucault (2008).

\begin{tabular}{|c|c|c|c|c|}
\hline Revista Dialectus & & n. 11 & Agosto - Dezembro 2017 & p. $50-68$ \\
\hline
\end{tabular}


A terceira diferença entre "disciplina" e "segurança" está no fato de que as disciplinas dividem as coisas em "obrigatório" e "proibido". Como aponta Foucault (2008), uma disciplina eficiente é a que diz, insistentemente, o que se deve fazer, diferentemente do código legal propriamente, o qual versa mais sobre o proibido, à luz de um pensamento negativo. Portanto, diferentemente da lei que proíbe, a disciplina - ao versar sobre o obrigatório - prescreve!

Já os mecanismos de segurança não adotam nem o ponto de vista do que é impedido, nem o ponto de vista do que é obrigatório. Ao contrário, buscam apreender o ponto em que as coisas vão se produzir, sejam elas desejáveis ou não (FOUCAULT, 2008). E isso é fundamental para pensarmos na categoria bullying no contemporâneo, emergindo nos dispositivos de segurança.

Em outras palavras, a lei proíbe, a disciplina prescreve e a segurança, sem proibir nem preservar, mas dando-se evidentemente alguns instrumentos de proibição e de prescrição, a segurança tem essencialmente por função responder a uma realidade de maneira que essa resposta anule essa realidade a que ela responde - anula, ou limite, ou freie, ou regule. Essa regulação no elemento da realidade é que é, creio eu, fundamental nos dispositivos de segurança. Poderíamos dizer também que a lei trabalha no imaginário, já que a lei imagina e só pode ser formulada imaginando todas as coisas que poderiam ser feitas e não devem ser feitas. Ela imagina o negativo. A disciplina trabalha, de certa forma, no complementar da realidade. O homem é malvado, o homem é ruim, ele tem maus pensamentos, tendências más, etc. Vai-se constituir, no interior do espaço disciplinar, o complemento dessa realidade, prescrições, obrigações, tanto mais artificiais e tanto mais coercitivas por ser a realidade o que é e por ser ela insistente e difícil de se dobrar. Enfim, a segurança, ao contrário da lei que trabalha no imaginário, e da disciplina que trabalha no complementar da realidade, vai procurar trabalhar na realidade, fazendo os elementos da realidade atuarem uns em relação aos outros, graças e através de toda uma série de análises e disposições específicas. (FOUCAULT, 2008, p. 60).

Por fim, outro ponto discutido por Foucault sobre as características da sociedade da segurança, particularmente na aula do dia 25 de janeiro de 1978, concerne à forma de normalização específica da segurança, se comparada com as tecnologias disciplinares. Nesse esforço de diferenciar os tratamentos que a disciplina e a segurança dão à normalização, Foucault (2008) pontua que as técnicas disciplinares tratam muito mais de uma "normação" do que de uma "normalização", como se percebe nas tecnologias de segurança.

Esse pensador francês caracteriza essa "normação" disciplinar mediante quatro aspectos: 1) a disciplina opera por um quadriculamento que decompõe, compõe e analisa os gestos, as ações, os espaços e tempos do indivíduo, não só para percebê-lo,

\begin{tabular}{|l|l|l|l|l|}
\hline Q Rovista 2 ialectus & Ano 4 & n. 11 & Agosto - Dezembro 2017 & p. 50-68 \\
\hline
\end{tabular}


como para transformá-lo; 2) ao identificar os elementos, a disciplina trata de classificálos a partir de determinados objetivos. Por isso, comumente assistimos a esforços, no contexto escolar, para responder que criança é mais ou menos apta para determinada tarefa, por exemplo; 3) a normação disciplinar visa a instituir sequências e coordenações ótimas entre os gestos, distribuindo, a título de ilustração, as crianças em hierarquias no território escolar; 4) seria próprio da disciplina também criar procedimentos que Foucault (2008) chama de adestramento progressivo e controle permanente, para sedimentar a demarcação entre aptos, inaptos, capazes, incapazes, etc.

Assim, a normação disciplinar inicialmente constrói e impõe um modelo ótimo em função de certo resultado esperado, sendo tarefa da disciplina conformar os indivíduos a esse modelo, escreve Foucault (2008). Ou seja, na disciplina temos uma "normação", pois o que é fundamental e primeiro nessa tecnologia de poder é a "norma", em função da qual se torna possível determinar e identificar quem são os normais - aqueles que são capazes de se conformar à norma - e quem são os anormais.

Por seu turno, a "normalização" que caracteriza os dispositivos de segurança se dá diferentemente. Foucault (2008, p. 77-78) usa o exemplo de questões de escassez de alimentos e de epidemias como a varíola, esclarecendo-nos que, a respeito da normalização das sociedades da segurança,

[...] enquanto os regulamentos jurídico-disciplinares que haviam reinado até
meados do século XVIII procuravam impedir o fenômeno da escassez
alimentar, o que se procurou, a partir de meados do século XVIII [...] foi
apoiar-se no próprio processo de escassez alimentar, na espécie de oscilação
quantitativa que produzia ora a abundância, ora a escassez, apoiar-se na
realidade desse fenômeno, não procurar impedi-lo, mas ao contrário fazer
funcionar em relação a ele outros elementos do real, de modo que o
fenômeno de certo modo se anulasse.

Sob esse ponto de vista, opera-se, no interior das tecnologias de segurança, cada vez mais com a racionalização do acaso e da probabilidade. Foucault (2008) ainda frisa que, a partir daí, as doenças, por exemplo, figurarão cada vez mais como distribuição de casos em uma população que será circunscrita num tempo e num espaço, e não como doenças reinantes, ligadas a um país, a uma cidade, a um clima ou a um conjunto de pessoas. Busca-se, desse modo, e com os casos de bullying isso não se faz diferente, coletivizar, quantificar e racionalizar os fenômenos individuais, para fins de melhor identificação da distribuição dos casos. Dessa maneira, a normalização encerrada nos dispositivos de segurança se empenhará em identificar, no indivíduo e nos grupos, os

\begin{tabular}{|l|l|l|l|l|}
\hline Gevista 2 ialectus & Ano 4 & n. 11 & Agosto - Dezembro 2017 & p. 50-68 \\
\hline
\end{tabular}


riscos de se adquirir doença e de se curar dela, bem como os riscos de desenvolver determinados comportamentos indesejáveis, como a violência infanto-juvenil, dependendo de sua idade, seu lugar de moradia, seu contexto de interação, etc.

Uma vez que o cálculo probabilístico presume que os riscos não são os mesmos para todos, independentemente de sua idade e de suas condições, a normalização dos dispositivos de segurança possibilita identificar zonas, indivíduos e grupos em maior e menor perigo, dentro de uma população. Portanto, vemos que, nas sociedades da segurança, emergem a noção de "risco", "perigo" e "crise" como novas tecnologias de controle, as quais se voltam para a população, e não só para o indivíduo.

Não surpreende, portanto, que, nesse contexto, a escola tenha se configurado, aos olhos de diversos segmentos midiáticos, de discursos científicos e de boa parte dos próprios atores escolares, um território da insegurança.

E que articulação podemos fazer entre essas questões e a emergência da categoria bullying e os contornos que as discussões a esse respeito têm tomado?

Como efeito da sociedade de segurança, temos uma sociedade que amplifica processos de governamentalização pelo crime ou pela infração. A partir dos dispositivos de criminalização, trata-se de incriminar para governar mais eficientemente. Aprimoram-se, segundo Candiotto (2012), a normalização, nas sociedades da segurança, pelo signo da delinquência. Seria esse um dos pontos que criam os rótulos de "agressor" e "vítimas" para crianças e adolescentes que protagonizam conflitos categorizados atualmente como bullying? Cada vez mais, conforme aquele autor, temos uma maneira de governar que permite e tolera a delinquência em sua realidade, a fim de, posteriormente, regulá-la por meio de dispositivos de segurança que configuram uma nova economia de poder que amplifica o controle sobre os corpos, sob uma lógica punitivo-penal cada vez mais intensa.

A emergência da categoria bullying está relacionada com a invenção de novas formas de gerir a violência nos últimos anos. Essas reflexões nos conduzem a discutir outro ponto: a articulação entre o fenômeno bullying e a gestão das condutas a ele concernentes como efeitos e instrumentos de governamentalização dos segmentos infanto-juvenis no contemporâneo.

Perspectivas de gestão calculista dos riscos em relação ao bullying são analisadoras de nossos modos de subjetivação atuais, nos contextos de uma sociedade de polícia, cuja regulação biopolítica se dá a partir de dispositivos de segurança

\begin{tabular}{|l|l|l|l|l|}
\hline Q & Oovista & n. 11 & Agosto - Dezembro 2017 & p. 50-68 \\
\hline
\end{tabular}


relacionados a um conjunto formado por instituições, procedimentos, análise e reflexões, cálculos, táticas visando à população, exercício de poder que Foucault (2008) chama de governamentalidade.

Outra forma de gerir o bullying, muito relacionada à gestão contemporânea da violência infanto-juvenil, é a instalação de câmeras e sistemas de monitoramento eletrônico. Em que pesem as controvérsias desses usos, devido às polêmicas quanto à privação de liberdade e dos direitos individuais, muitos atores escolares e segmentos da sociedade em geral vêem essas medidas como facilitadoras do combate às várias formas de violência escolar, o que têm repercutido no aumento do consumo desses dispositivos de segurança (BONAMIGO, 2008). Clamam-se operações policiais, revistas e câmeras nas escolas. Concordamos com Sibilia (2012) que tais operações parecem almejar não só a atualização tecnológica do panóptico, modelo arquitetônico tipíco dos estabelecimentos disciplinares modernos. A utilização de sistemas de câmeras e monitoramento eletrônico para fazer frente a dificuldades que vêm agoniando essa fatigada escola, entre elas o bullying, assinala, principalmente, o controle da insegurança, questão tipicamente contemporânea.

Não raro, as vozes que denunciam o bullying são as mesmas que rogam por segurança por meio de ordem e controle. Afinal, parece-nos que, para legitimar esse controle da insegurança, fundamental se torna que as práticas de bullying e os dados estatísticos abundem e se espetacularizem na mídia.

O que essas formas de gestão do bullying indicam? Pensamos que, dentre outras questões, elas nos sinalizam para a "emergência de uma sociedade que reforça um Estado Penal, mais preocupado em reprimir a violência e o crime que em manter políticas públicas voltadas para a manutenção do bem-estar social (BONAMIGO, 2008, p. 204)". Além disso, a articulação entre a fabricação da noção de bullying e o recrudescimento de dispositivos de segurança e da noção de risco, no contexto de um controle biopolítico das populações infanto-juvenis, sinaliza justamente um traço da crise em meio a qual se encontra a escola hoje, já que implica dramático esvaziamento do dispositivo pedagógico da escola ante o enfrentamento da violência escolar entre colegas.

Corroboramos com Banamigo (2008, p. 205), que aponta, em relação à violência de um modo geral, em diálogo com Guattari e Rolnik, ser necessário buscar

\begin{tabular}{|l|l|l|l|l|}
\hline Gevista 2 ialectus & Ano 4 & n. 11 & Agosto - Dezembro 2017 & p. 50-68 \\
\hline
\end{tabular}


[...] a subversão dos processos de subjetivação, que estão em curso, de forma a evidenciá-los e a produzir subjetividades delirantes, que num embate com a subjetividade capitalística, a façam desmoronar, propiciando o agenciamento de singularidades que, por exemplo, permitam acolher a multiplicidade, a complexidade, a imprecisão e a indeterminação presentes nos processos de fabricação, inscrição, tradução e gestão das violências.

Seria possível encetar movimentos de resistência e criação frente a essa gestão do bullying, agenciando singularidades e outros modos de conceber essas questões?

\section{Considerações finais: conexões entre Bullying e os processos de judicialização da vida.}

Neste tópico, será ressaltado como o bullying opera como dispositivo de judicialização infanto-juvenil. Em diálogo com o pensamento foucaultiano, entendemos aqui a judicialização da vida como um processo caracterizado pelo enquadramento jurídico-legal cada vez mais minucioso das relações sociais (LOBO, 2012; MARAFON, 2013).

Em algumas produções científicas sobre a temática do bullying, a escola aparece como lócus de "detecção", "prevenção" e "combate" à violência entre pares (FANTE, 2005; SILVA, 2010; MALTA et. al, 2010; CARVALHO; SILVA, 2011). Ora se defende seus direitos à proteção, ora se judicializam esses segmentos mediante a operação de tecnologias de coerção, regulação e criminalização de condutas infantojuvenis.

Silva (2010), por exemplo, aponta o que ela chama de "passos" a serem seguidos pelas escolas: 1) reconhecimento do problema; 2) capacitação dos profissionais para identificar, diagnosticar, intervir e encaminhar os casos; 3) mobilização do entorno para ações preventivas e imediatas; 4) busca de consultorias externas de profissionais de diversas áreas, como psicólogos, médicos e assistentes sociais, bem como de parcerias com outras instituições públicas, como Conselhos Tutelares, Delegacias da Criança e do Adolescente e Varas da Infância e Juventude.

É possível notar como signos familiares a enquadres jurídicos atravessam as discursividades sobre como a escola deve lidar com o bullying. Senão vejamos: com relação ao posicionamento dos professores, Silva (2010, p.169) recomenda que eles, ao identificarem casos de bullying, devem se dirigir à direção da escola a fim de que ela "realize uma sindicância (ou averiguação) interna [grifo nosso] e tome as decisões necessárias sobre as condutas e procedimentos que devem ser adotados. [...]”.

\begin{tabular}{|c|c|c|c|c|}
\hline Ronista Dialectus & Ano 4 & n. 11 & Agosto - Dezembro 2017 & p. $50-68$ \\
\hline
\end{tabular}


O tratamento dado pela literatura científica acerca do papel da escola na "resolução" do famigerado bullying é um potente analisador de como, segundo Foucault (1996), o sistema escolar opera nas adjacências do poder judiciário, podendo punir sem que necessariamente haja crime, pena, juiz, etc. Trata-se, como ressalta Lemos (2013, p.174), de um tipo de punição aos desviantes da norma e de um mini tribunal onde os educadores, os especialistas, os próprios alunos e familiares que

\footnotetext{
[...] se vigiam, que se controlam, que se observam, mensuram suas vidas no tempo e no espaço, que sancionam uns aos outros em pareceres, em laudos, em encaminhamentos, em denúncias administrativas, em carimbos e assinaturas, em livros de anotação, em advertências e recomendações, em enquadramentos disciplinares próximos à racionalidade jurídica, sendo judicializante pelas normas na relação com as leis sem a ação direta dos operadores do direito e, em algum momento, podendo estar com eles e ao lado deles.
}

A partir de um trabalho de pesquisa-intervenção em uma escola pública do Nordeste brasileiro, Barros (2014) pontua que, além de psicólogos e médicos, cada vez mais Conselho Tutelar, Guarda Municipal e Polícia Militar têm sido convocados pela organização escolar para resolver alguns de seus conhecidos problemas, dentre eles os conflitos entre pares na forma de intimidação, agressões verbais e agressões físicas significados no cotidiano como bullying. Esses aspectos, também trabalhados em produções da psicologia como a de Heckert e Rocha (2012), remetem ao debate sobre a intensificação de processos de judicialização da vida por meio de práticas institucionais discursivas e não discursivas sobre bullying no território escolar.

Não obstante, a judicialização dos segmentos infanto-juvenis não é um processo propriamente novo, pois já podia ser percebida, por exemplo, na tessitura da categoria "menor", fabricada em nosso país entre o final do século XIX e início do século XX, a partir da articulação entre maquinarias judicializantes e médicohigienistas, com vista à gestão calculista de segmentos infanto-juvenis pauperizados, subjetivados como problema social (MARAFON, 2013).

Com base nisso, concordamos com a seguinte tese defendida por Marafon (2014): a fabricação da aludida menoridade e a ideia de prevenção ao bullying fazem parte de um continuum no processo de judicialização das vidas infanto-juvenis, configurando-se, cada uma a seu modo, como mecanismos de controle biopolítico dessas populações.

\begin{tabular}{|l|l|l|l|l|}
\hline Q Rovista 2 ialectus & Ano 4 & n. 11 & Agosto - Dezembro 2017 & p. 50-68 \\
\hline
\end{tabular}


Apesar de considerarmos que o fenômeno da judicialização não é recente, entendemos que se trata de uma tendência que ganha novos contornos atualmente, não só no Brasil, diga-se de passagem. Como um dos principais sinais disso, assistimos à ampliação da presença de dispositivos jurídicos mediando as relações sociais.

Em sua análise de um texto de Foucault que discute a redefinição do judiciável, Lobo (2012) realça a difusão das funções judiciárias por todo o corpo social na contemporaneidade. Segundo o pensamento de Foucault, a regulamentação jurídica dos comportamentos, já em formação desde meados do século XX, expressa os aprimoramentos e as capilarizações das tecnologias de poder.

$\mathrm{Na}$ paisagem contemporânea, a perspectiva de que o indivíduo é um “empresário de si mesmo" ganha mais espaço (FOUCAULT, 2008, p. 311). Um dos efeitos disso é a exacerbação dos atos de violência. Como expõe o próprio Foucault (2008, p. 240),

[...] quanto mais a lei dá aos indivíduos a possibilidade de se comportar como querem na forma de livre empresa, mais se desenvolvem na sociedade essas formas múltiplas e dinâmicas de unidade empresa, mais, ao mesmo tempo, as superfícies de atrito entre essas diferentes unidades são numerosas e grandes, mais as ocasiões de conflito, mais as ocasiões de litígio se multiplicam.

Sobre a forma como o dispositivo-bullying potencializa esses processos de judicialização dos conflitos entre pares na escola, concordamos com Marafon (2013) que, na trama escolar, as situações litigiosas entre tais "empresários de si mesmos" têm acarretado a ampliação da demanda por mais ação contenciosa na qual se multiplicam “juízes” na escola e intervenções judiciárias no intuito de arbitrarem essas relações de conflito. Por meio das práticas de judicialização dos conflitos escolares, o dispositivobullying ratifica a ideia de que não só as "causas", como os próprios "manejos" da violência entre pares, radicam-se sobretudo fora da escola, o que despotencializa o coletivo da escola. Em tempos de medicalização e judicialização da vida escolar, a função de seus profissionais frente aos atos violentos passa a ser muito mais de detecção e encaminhamento do que de intervenção propriamente.

Em sua cartografia da violência infanto-juvenil no território escolar, Barros (2014) expôs que essa tendência judicializante se faz sentir na escola à medida que os conflitos relacionais nesse contexto são tratados por meio da transposição de enquadres jurídicos. Um dos exemplos dessa tendência é uma segmentação dura expressa pela

\begin{tabular}{|l|l|l|l|l|}
\hline Govista Dialectus & Ano 4 & n. 11 & Agosto - Dezembro 2017 & p. 50-68 \\
\hline
\end{tabular}


busca de encaixar os envolvidos nas situações de violência tidas como bullying em categorias binarizantes do tipo "vítima" e "agressor".

A multiplicação de objetos jurídicos amplifica conflitos e litígios, dando-lhes também novas significações (MARAFON, 2013). Barros (2014) aponta como, nesse processo, o próprio papel do professor se redefine também: o que agora é visto como violência passa a ser muito mais de um domínio jurídico-legal que de uma alçada educacional. De acordo com Foucault (2008a, p. 251), a “contratualização da vida comum", que se espraia nas interações sociais e se manifesta pela ampliação de regras e regulações burocráticas, é um dos desdobramentos do neoliberalismo contemporâneo. Tomemos como orientador o que escreve Lobo (2012), a partir de um olhar genealógico:

\footnotetext{
Parece estar acontecendo um processo de inversão do poder judiciário em comparação com o século XIX, quando uma rede institucional não judiciária desempenhava funções que hoje estão sendo gradativamente atribuídas à justiça. O controle dos comportamentos e das populações continua funcionando nesta rede de vigilância e correção em instituições como a escola, a polícia, a psiquiatria, mas certamente vem transferindo seu poder decisório e seu objetivo de prevenir e corrigir as virtualidades da infração para o poder judiciário (LOBO, 2012, p. 29).
}

A partir de grupos de discussão sobre violência escolar com professores de uma escola pública, Barros (2014) observa uma das marcas desses atravessamentos jurídicos nas questões educacionais: a demanda para que se reforçasse o aparato legal contra o bullying, sem o que os profissionais alegavam se sentir "enxugando gelo". Naquele contexto de pesquisa, alguns professores queixavam-se por não existirem leis mais rígidas capazes de evitar atos de violência na escola.

A cartografia de Barros (2014) corrobora, portanto, as reflexões trazidas por Lobo (2012), para quem, no contexto de redefinição do que é judiciável, a lei assume cada vez mais uma função pedagógica. Por seu turno, a sensação de impotência e desamparo dos professores diante da carência de um aparato legal antibullying nos fez dar sentido ao que escreve Marafon (2014, p. 145):

O modo como a identificação bullying se disseminou por meio de cursos, programas de prevenção, capacitações para professores, projetos de lei, etc., disponibilizando recursos e pessoas a essa finalidade, apresenta cumplicidade com a ampla deslegitimação da escola como instituição educativa em nossa sociedade.

\begin{tabular}{|l|l|l|l|l|}
\hline Q Rovista 2 ialectus & Ano 4 & n. 11 & Agosto - Dezembro 2017 & p. 50-68 \\
\hline
\end{tabular}


Portanto, a visibilidade dada ao bullying não necessariamente sugere aprimoramento dos mecanismos de proteção dos segmentos infanto-juvenis e problematização da ordem que institui e trivializa esses atos violentos entre segmentos infanto-juvenis. Ao contrário, determinadas discursividades agenciadas pela "literatura científica especializada" no assunto indicam um aperfeiçoamento das tecnologias de governamentalização neoliberal dessas populações.

Ao discutir a temática da governamentalidade e da educação, Veiga-Neto (2011) ressalta que, desde meados do século $\mathrm{XX}$, o neoliberalismo vem se constituindo como um ethos, um modo de vida, o que faz com que a escola, por exemplo, seja vista fundamentalmente como uma instituição cujo encargo é fabricar novas subjetividades, ao invés de tão-somente ser um lugar onde se ensina e se aprende ideologias. Para esse autor, a característica principal do neoliberalismo como uma forma de governamentalidade é que a competição tem se transformado na forma por meio da qual se produz e se exerce a liberdade.

\section{REFERÊNCIAS:}

ANTUNES, D. C. Bullying: razão instrumental e preconceito. 1. ed. São Paulo: Casa do Psicólogo, 2010, v. 1. 243p.

BARROS, J.P.P. Violência infantojuvenil e o território da escola: o bullying como analisador de processos de subjetivação contemporâneos. 292 f. Tese (doutorado) Universidade Federal do Ceará, Faculdade de Educação, Programa de Pós-Graduação em Educação Brasileira, Fortaleza, 2014.

BONAMIGO, I. S. Violências e processos contemporâneos de subjetivação. In: BONAMIGO, I. S.; TONDIN, C. F.; BRUXEL, K. (Org.). As práticas da psicologia social $\operatorname{com}(0)$ movimentos de resistência e criação. 1ed.Porto Alegre: Abrapso Sul, 2008, v. 1, p. 195-206.

CANDIOTTO, C. Disciplina e segurança em Michel Foucault: a normalização e a regulação da delinquência. Psicologia e Sociedade, vol.24 (no.spe), Belo Horizonte, 2012.

CARVALHO, A. A. T; SILVA, M. L. O bullying e a gestão democrática de escolas públicas. Olhares Plurais - Revista Eletrônica Multidisciplinar, v. 1, n. 4, p. 81-98, 2011.

DELEUZE, G. Foucault. São Paulo: Brasiliense, 1998.

FANTE, C. Fenômeno bullying: Como prevenir a violência nas escolas e educar para a paz $-2^{\mathrm{a}}$ ed. - Campinas, SP: Versus, 2005.

\begin{tabular}{|l|l|l|l|l|}
\hline Gevista 2 ialectus & Ano 4 & n. 11 & Agosto - Dezembro 2017 & p. 50-68 \\
\hline
\end{tabular}


MARAFON, G. Vidas em Judicialização: efeito bullying como analisador. 2013. $163 \mathrm{f}$. Tese (Doutorado em Psicologia) - Programa de Pós-Graduação em Psicologia, Universidade Federal Fluminense, Niteroi-RJ, 2013a.

FOUCAULT, M. Ditos e Escritos. Paris: Gallimard, v. 5, 1995.

A verdade e as formas jurídicas. Rio de Janeiro: Nau, 1996.

Graal, 2000.

Sobre a história da sexualidade. In: Microfísica do Poder. Rio de Janeiro:

Segurança, Território, População. São Paulo: Martins Fontes, 2008.

O sujeito e o poder. In: DREYFUS, H; RABINOW, P. Michel Foucault: uma trajetória filosófica para além do estruturalismo e da hermenêutica. Rio de Janeiro: Forense Universitária, 2010.

HECKERT, A.L.C; ROCHA, M. L. A maquinaria escolar e os processos de regulamentação da vida. Psicologia \& Sociedade, 24(n.spe.): 85-93, 2012.

LEMOS, F. C. S. A judicialização da vida no campo das relações entre a norma e a lei: mecanismos de poder e resistência na assistência social e na saúde. . In: BRIZOLA, A. L.; ZANELlA, A.V.; \& GESSER, M. (Orgs). Práticas Sociais, políticas públicas e direitos humanos. 1ed.Florianópolis: ABRAPSO-NUPPE/CFH/UFSC, 2013, v. 1, p. 171-180.

LEMOS, F. C. S; BICALHO, P.P.G; ALVAREZ, M. C.; BRÍCIO, V. N. Governamentalidades neoliberais e dispositivo de segurança. Psicologia \& Sociedade, v. 27, n. 2, p. 332-340, 2015.

LOBO, L. F. Os Infames da História: pobres, escravos e deficientes no Brasil. Rio de Janeiro: Lamparina, 2008.

MALTA, D.C; SILVA, M.A.I; MELLO, F.C.M; MONTEIRO, R.A; SARDINHA, L.M.V; CRESPO, C; CARVALHO, M.G.O; SILVA, M.M.A; PORTO, D. L.Bullying nas escolas brasileiras: resultados da Pesquisa Nacional de Saúde do Escolar (PeNSE) 2009. Revista Ciência \& Saúde Coletiva, Rio de Janeiro, v. 15(Supl. 2), p. 3065-3076, 2010 .

MARAFON, G. Vidas em Judicialização: efeito bullying como analisador. 2013. 163f. Tese (Doutorado em Psicologia) - Programa de Pós-Graduação em Psicologia, Universidade Federal Fluminense, Niteroi-RJ, 2013a.

. Políticas da vida hoje: o 'fenômeno' bullying ou como recusar o que somos. In: COLlARES, C. A. L; MOYSÉS, M. A. A.; RIBEIRO, M. C. F.. (Org.). Novas capturas, antigos diagnósticos na era dos transtornos. 1ed. Campinas: Mercado de Letras, 2013b, v. 1, p. 133-148.

. Judicialização da infância: da menoridade à prevenção do bullying. Revista entreideias: educação, cultura e sociedade, v. 3, p. 79-93, 2014.

\begin{tabular}{|l|l|l|l|l|}
\hline Govista Dialectus & Ano 4 & n. 11 & Agosto - Dezembro 2017 & p. 50-68 \\
\hline
\end{tabular}


SIBILIA, P. Redes ou paredes: a escola em tempos de dispersão. Rio de Janeiro: Contraponto, 2012.

SILVA, A.B.B. Bullying: mentes perigosas nas escolas. Rio de Janeiro: Objetiva, 2010. 